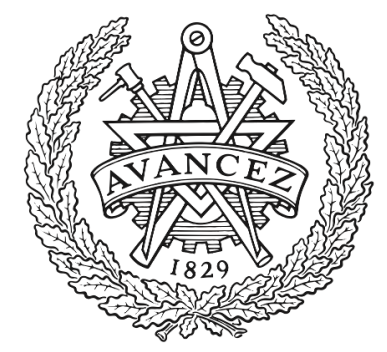

CHALMERS

UNIVERSITY OF TECHNOLOGY

\title{
Low plasticity burnishing improves fretting fatigue resistance in bone-anchored implants for amputation prostheses
}

Downloaded from: https://research.chalmers.se, 2023-04-26 08:26 UTC

Citation for the original published paper (version of record):

Thesleff, A., Ortiz Catalan, M., Brånemark, R. (2022). Low plasticity burnishing improves fretting fatigue resistance in bone-anchored implants for amputation prostheses. Medical Engineering and Physics, 100. http://dx.doi.org/10.1016/j.medengphy.2022.103755

N.B. When citing this work, cite the original published paper. 


\title{
Low plasticity burnishing improves fretting fatigue resistance in bone-anchored implants for amputation prostheses
}

\author{
Alexander Thesleff a,b,c, , Max Ortiz-Catalan ${ }^{\mathrm{a}, \mathrm{b}, \mathrm{d}, \mathrm{e}}$, Rickard Brånemark ${ }^{\mathrm{e}, \mathrm{f}}$ \\ ${ }^{a}$ Center for Bionics and Pain Research, Mölndal, Sweden \\ ${ }^{\mathrm{b}}$ Department of Electrical Engineering, Chalmers University of Technology, Gothenburg, Sweden \\ ${ }^{\mathrm{c}}$ Integrum AB, Mölndal, Sweden \\ d Operational Area 3, Sahlgrenska University Hospital, Mölndal, Sweden \\ e Department of Orthopaedics, Institute of Clinical Sciences, Sahlgrenska Academy, University of Gothenburg, Sahlgrenska University Hospital, Gothenburg, Sweden \\ ${ }^{\mathrm{f}}$ Center for Extreme Bionics, Biomechatronics Group, MIT Media Lab, Massachusetts Institute of Technology, Cambridge, MA, USA
}

\section{A R T I C L E I N F O}

\section{Keywords:}

Osseointegration

Bone-anchored attachment

Direct skeletal attachment

Osseointegrated prostheses for the

rehabilitation of amputees (OPRA)

OPRA

Low plasticity burnishing

Fretting fatigue

Mechanical testing

\begin{abstract}
A B S T R A C T
Fretting fatigue is a common problem for modular orthopedic implants which may lead to mechanical failure of the implant or inflammatory tissue responses due to excessive release of wear debris. Compressive residual stresses at the contacting surfaces may alleviate the problem. Here we investigate the potential of a surface enhancement method known as low plasticity burnishing (LPB) to increase the fretting fatigue resistance of boneanchored implants for skeletal attachment of limb prostheses. Rotation bending fatigue tests performed on LPB treated and untreated test specimens demonstrate that the LPB treatment leads to statistically significantly increased resistance to fretting fatigue (LPB treated test specimens withstood on average 108,780 load cycles as compared with 37,845 load cycles for untreated test specimens, $p=0.004$ ). LPB treated test specimens exhibited less wear at the modular interface as compared with untreated test specimens. This surface treatment may lead to reduced risk of fretting induced component failure and a reduced need for revision of implant system componentry.
\end{abstract}

\section{Introduction}

The traditional method for attaching a limb prosthesis to the body is by a socket compressing around the skin and soft tissues of the residual limb. However, the socket-stump interface commonly causes problems such as discomfort, skin problems, poor retention, and perspiration [1-6]. Another way to attach the prosthesis is by anchoring it to the bone. This can be achieved via osseointegration, which is the "firm anchoring of a surgical implant by the growth of bone around it without fibrous tissue formation at the interface" [7]. The first clinical applications of osseointegration were in the dental field [8], but since 1990, it has also been used for skeletal attachment of limb prostheses [9]. The method was developed in Sweden and the first implant system for this purpose is known as the OPRA (Osseointegrated Prostheses for the Rehabilitation of Amputees) Implant System, (Integrum AB Mölndal, Sweden). In 1999, this implant system was CE marked and standardized along with its surgical technique and rehabilitation protocol for transfemoral amputations. Since then, prospective clinical trials have shown that treatment with the OPRA Implant System leads to increased quality of life, increased prosthetic usage, improved mobility and reduced prosthesis related problems compared with conventional socket prostheses [10-12]. Similar findings have been reported with other implants for skeletal attachment of limb prostheses [13-15].

The OPRA Implant System has a modular design consisting of a fully implanted fixture, a percutaneous abutment, and an abutment screw (Fig. 1a). In a first surgical procedure, the externally threaded fixture is implanted into the residual bone. The fixture is osseointegrated forming a firm connection between the bone and the fixture [16]. In a second surgical procedure, the abutment is implanted. The proximal end of the abutment is inserted into the fixture with a stable connection achieved by a cylindrical press-fit. The distal end of the abutment protrudes through the skin. The connection between the fixture and the abutment is further stabilized by a preload which is applied via the abutment screw.

The reduction in prosthesis related problems and the improved mobility with the prosthesis leads to more prosthesis usage and higher

\footnotetext{
* Corresponding author: Integrum AB, Krokslätts Fabriker 50, 43137 Mölndal, Sweden

E-mail address: thesleff@chalmers.se (A. Thesleff).
} 
a)

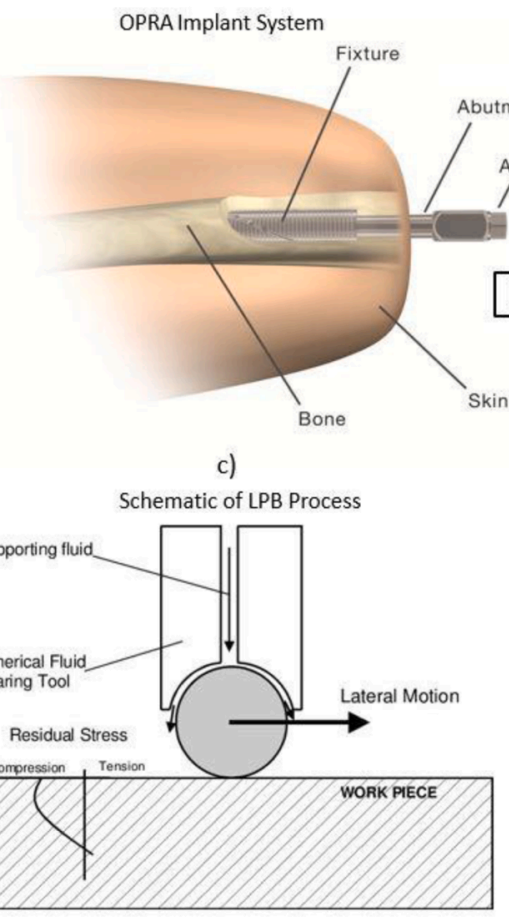

b)

Test components

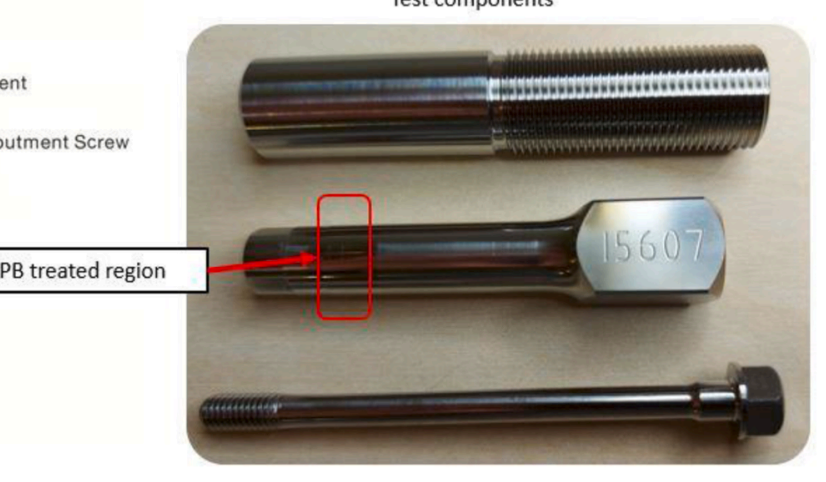

d)

Schematic cross-sectional view of assembled test specimen

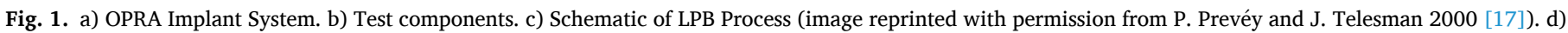
Schematic cross-sectional view of assembled test specimen.

activity levels for users with bone-anchored prostheses compared with conventional socket prostheses. This increased mechanical demand posed challenges for earlier designs of the implant system. For instance, the frequency of mechanical complications has been reported to increase in long-term follow-ups [18]. A series of design improvements, including, material change, and geometrical and dimensional changes has therefore been introduced in newer versions of the implant system $[18,19]$. Further improvements are being evaluated to meet future demand of even more active users, the use of powered prosthetic legs, and activities such as running. In this work, we present an experimental evaluation of low plasticity burnishing (LPB) to reduce fretting induced damage arising from long-term usage at high loads.

Fretting is small amplitude oscillatory movement between contacting surfaces [20]. It may lead to fretting corrosion by disruption of protective oxide films of the contacting surfaces, and fretting fatigue if one or both contacting surfaces are exposed to cyclic loading. The damage from the fretting action accelerates nucleation and early growth of fatigue cracks, reducing the mechanical strength and durability under continued loading. Fretting corrosion and fretting fatigue are known problems of modular orthopedic implants both due to negative tissue reactions from the wear debris and to premature fractures of the implant itself as a result of the fretting degradation [21-23]. In the OPRA Implant System, the interface between the fixture and the abutment may be subjected to fretting corrosion and fretting fatigue if exposed to excessive loading for a large number of load cycles. This could ultimately lead to failure of the abutment or the abutment screw.

It is known that compressive residual stresses at, and close to the surface of a material improve fatigue performance and resistance to fretting corrosion by delaying the onset of fatigue crack initiation [20]. Several methods exist for inducing compressive residual stresses, examples are shot peening, laser peening, deep rolling and LPB [24]. The LPB method, characterized by its ability to introduce compressive residual stresses extending deep below the surface has documented success in increasing fatigue life in compressor turbine blades [25], structural aircraft aluminum [26], and orthopedic hip implants with tapered interface connection [27]. Compressive residual stresses extending below the surface of the treated region may be beneficial also in press-fit cylindrical connections present in bone-anchored implants for amputation prostheses. The objective of this evaluation is to investigate the potential of LPB for increasing the resistance to fretting fatigue in this application with the ultimate aim of reducing the need and frequency of implant component revisions.

\section{Methods}

\subsection{Test specimens}

The test specimens consisted of components from the first generation of OPRA Implant System (Fig. 1b), manufactured from Ti6Al4V. The only components which were modified with respect to the components for clinical use were the fixtures, where the ones manufactured for mechanical testing had an external thread covering only half of its length to provide better fixation in the test rig (Fig. 1b and Fig. 1d). All components were manufactured using the same processes and materials as those used for clinical use. Measurements of critical geometrical features and dimensions were performed by the manufacturer, and it was verified that all components were within the specified tolerances for the implants that have been used clinically.

\subsection{Low plasticity burnishing}

The LPB process is characterized by a single pass of a smooth free rolling spherical ball under a normal force just sufficient to deform the surface of the material in tension, creating a compressive layer of residual stress (Fig. 1c) [28]. A difference compared with conventional burnishing methods is that the ball is supported in a spherical fluid bearing with sufficient pressure to lift the ball off the surface of the retaining socket. Thus, the ball is only in solid contact with the surface to be burnished. The normal force, fluid pressure, and tool position are controlled in a multi-axis CNC machine tool or lathe [28]. 


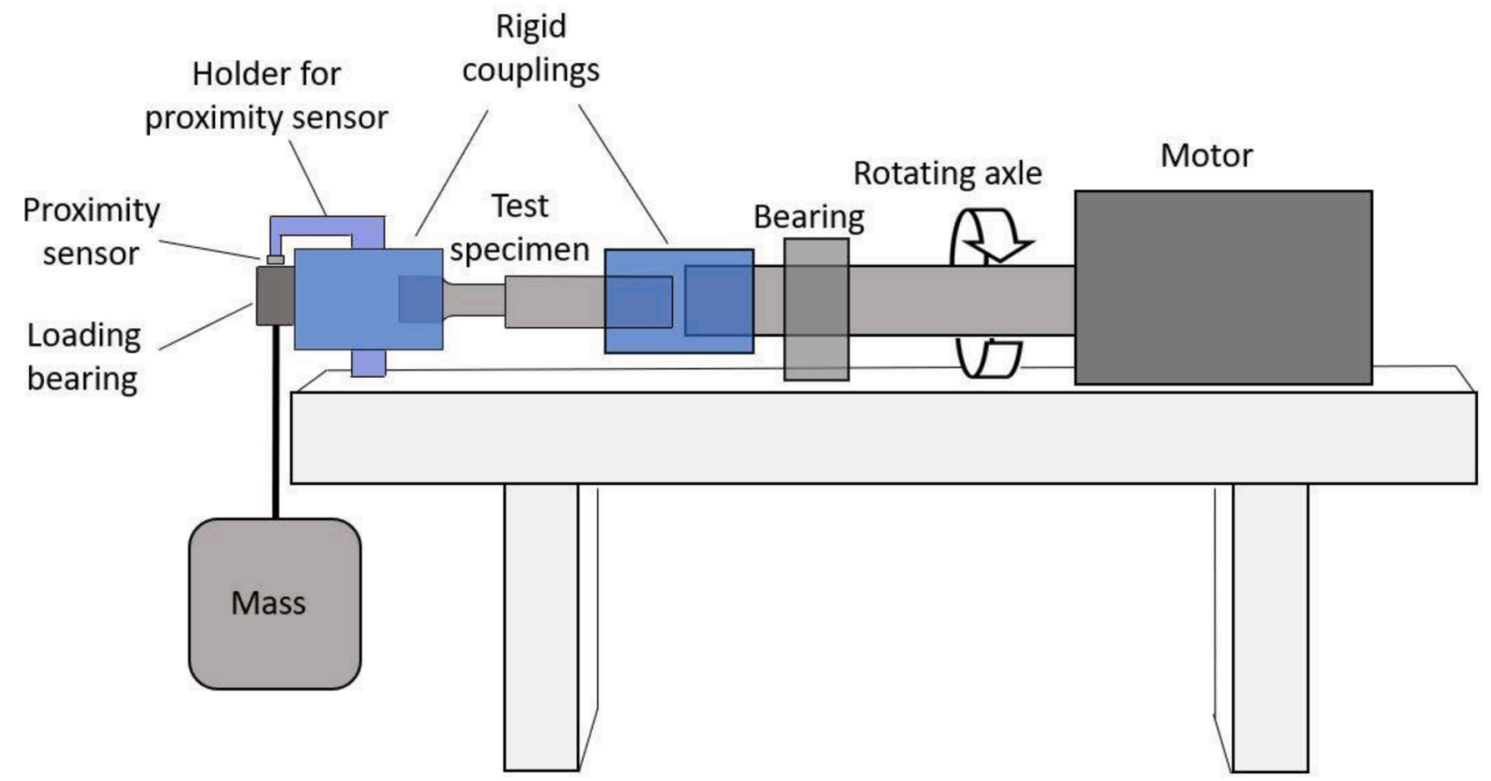

Fig. 2. Schematic illustration of test machine used for the rotation bending tests.

The manufactured abutments were divided into two groups, a control group and an LPB group. The latter underwent LPB processing in two stages. In the first stage, four abutments were used for process adjustments and residual stress measurements. The imparted residual stresses from the LPB treatment were verified by measurements using Xray diffraction of copper $\mathrm{K}_{\alpha 1}$ radiation from the 21.3 planes of the hexagonal close packed structure (HCP) of the $\alpha$-phase of the Ti6Al4V [29]. The measurements were done in the longitudinal direction at the center of the LPB treated region.

Once process adjustments were completed, the rest of the abutments in the LPB group underwent the treatment according to the established process specification. The procedure was performed on a circumferential band covering the interference-fit region at the proximal end of the abutment.

\subsection{Rotation bending test}

During ambulation, the OPRA Implant System is cyclically exposed to forces in several directions, torsional moments, and bending moments. Several studies have characterized the loading of the boneanchored implant during activities of daily living and revealed large inter-subject variations in the load cycle even during well-defined activities such as level ground walking [30-33]. This makes it challenging to generalize real-world loading of the implant to a single load cycle. Nevertheless, the same studies have confirmed that the stress state in the implant system is dominated by the contribution from bending moment induced during the stance face of the gait cycle [30-33]. Based on this information it was concluded that evaluation of the LPB treatment had to be conducted with a test method that considers the bending moments of the stance phase of the gait cycle. Repeatability and simplicity of the test setup was prioritized over the ability to include cyclic torsional moments and forces in multiple directions. A rotation bending test setup was therefore chosen as the evaluation method. This test method can be regarded as more severe than the clinical load case due to the fact the full circumference of the test specimen is exposed to a maximum fully reversed loading $(R=-1)$ every load cycle, thus maximizing wear, and likelihood of finding weak spots and material defects, thereby increasing the risk of fatigue crack initiation and propagation.

Test specimens were prepared by assembling the test components according to the clinical procedure, where the abutment is pressed into the fixture using an installation tool and the joint preload is achieved by applying torque on the abutment screw.

For each test, the specimen was rigidly attached in the test machine (Fig. 2) exposing the region of interest consisting of the threaded portion of the fixture and the abutment shaft. The bending load was achieved by placement of a $45.9 \mathrm{~kg}$ mass, vertically attached to the "free" end of the test specimen. The tests were performed at room temperature, at a frequency of $2.1 \mathrm{~Hz}$. The test location was a window-free basement facility with stable environmental conditions. Humidity levels were not recorded. The vertical displacement of the test specimen was tracked by an inductive proximity sensor (Contrinex, DW-ax-509-M8-390, Switzerland) (Fig. 2), which caused the test to automatically stop if the displacement exceeded a pre-specified threshold. After an initial "run in" period of 1,000 load cycles, the test was manually stopped and all fasteners holding the test specimen were retightened to ensure that the test specimens were rigidly attached in the test rig before restarting the test. After the test automatically stopped for the first time, the coupling between the test rig and the test specimen were inspected and retightened. The test was then resumed until it automatically stopped for a second time. This was done to ensure that the test was not stopped due to displacement in the connection between the test rig and the test specimen.

\subsection{Post-test inspections}

After completion of the rotation bending test, the components of the test specimen were disassembled by unscrewing the abutment screw and extracting the abutment from the fixture. A first inspection of individual components was performed using a light microscope. Each component was inspected for fatigue cracks, wear marks, and damage from the rotation bending tests.

\subsection{Scanning electron microscopy}

A more detailed examination of the contact surfaces of the fixture and the abutment was conducted using scanning electron microscopy (SEM), with Zeiss Ultra 55 Scanning Electron Microscope (Carl Zeiss Microscopy Deutschland GmbH, Germany).

\subsection{Interference profilometry}

To quantify the extent of wear at the internal cylindrical contact 


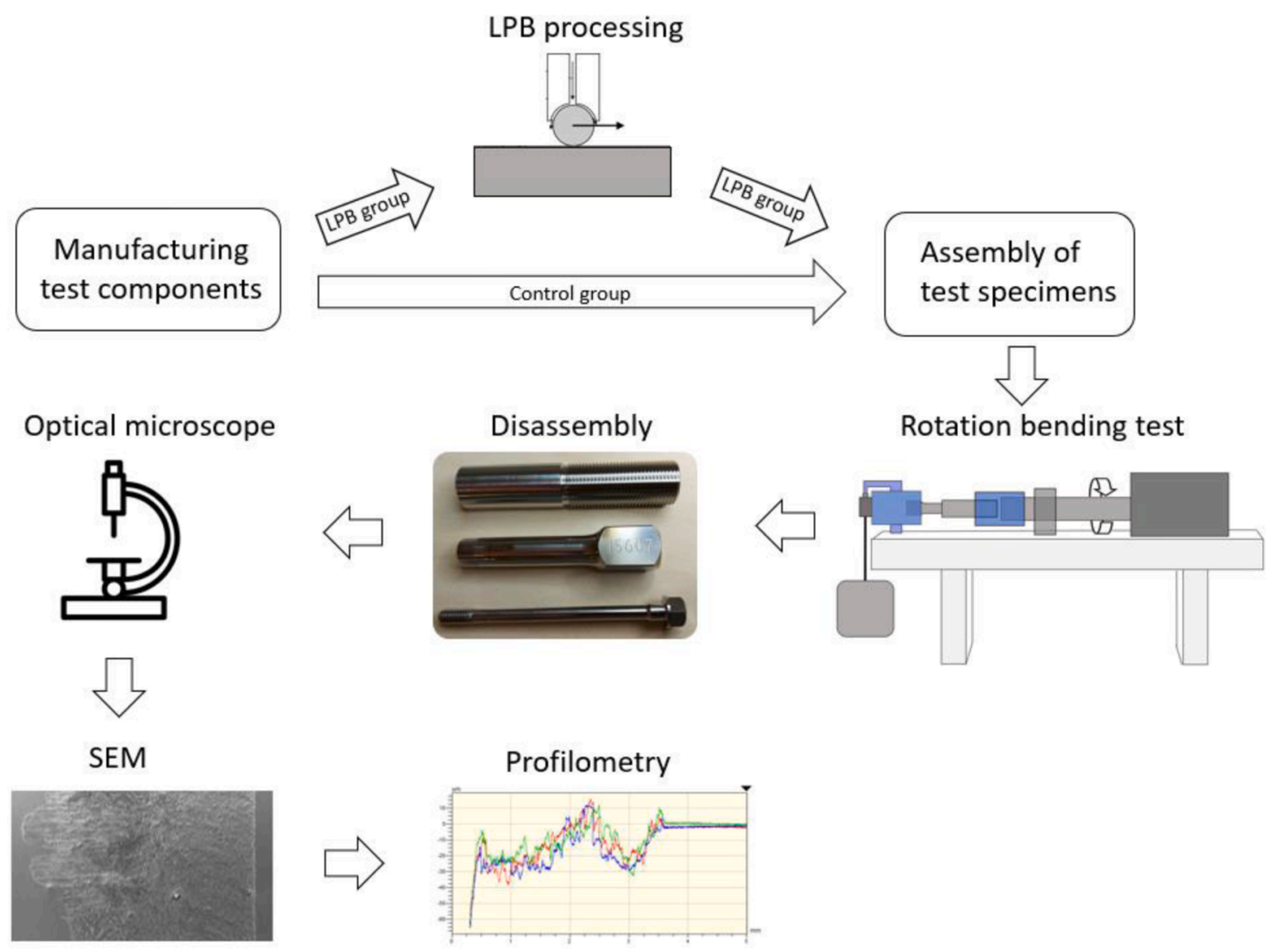

Fig. 3. Schematic illustration of the sequence of the study procedures including preparatory steps, rotation bending test, and post-test procedures.

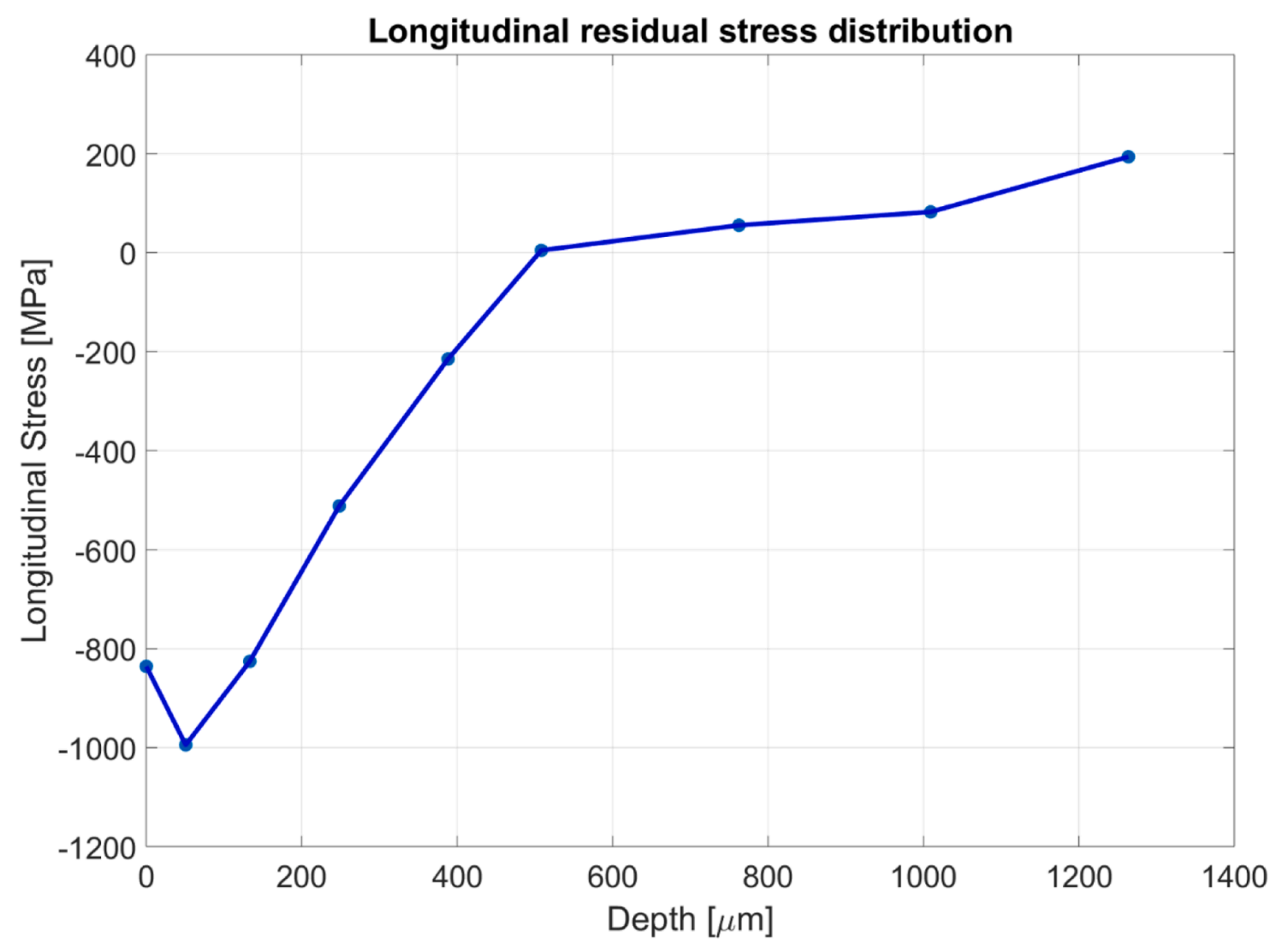

Fig. 4. Measured longitudinal residual stress at the center of the treated region in one of the LPB treated abutments. 
Table 1

Test results from rotation bending tests.

\begin{tabular}{|c|c|c|c|}
\hline $\begin{array}{l}\text { Test } \\
\text { Number }\end{array}$ & Test specimens & $\begin{array}{l}\text { Number of } \\
\text { load cycles }\end{array}$ & $\begin{array}{l}\text { Confirmed } \\
\text { crack / } \\
\text { Location }\end{array}$ \\
\hline 1 & Control 1 & 43,025 & $\begin{array}{l}\text { Yes / } \\
\text { Abutment } \\
\text { press-fit }\end{array}$ \\
\hline 2 & Control 2 & 40,896 & $\begin{array}{l}\text { Yes / } \\
\text { Abutment } \\
\text { press-fit }\end{array}$ \\
\hline 3 & Control 3 & 29,266 & $\begin{array}{l}\text { Yes / } \\
\text { Abutment } \\
\text { press-fit }\end{array}$ \\
\hline 8 & Control 4 & 38,191 & $\begin{array}{l}\text { Yes / } \\
\text { Abutment } \\
\text { press-fit }\end{array}$ \\
\hline \multirow[t]{2}{*}{ Control } & $\begin{array}{l}\text { Sample mean / Sample } \\
\text { standard deviation }\end{array}$ & 37,845 & / $\quad 6,051$ \\
\hline & $\begin{array}{l}\text { Sample median / Sample } \\
\text { median absolute deviation }\end{array}$ & 39,544 & / $\quad 2,417$ \\
\hline 4 & LPB 1 & 119,520 & $\mathrm{No}^{*}$ \\
\hline 5 & LPB 2 & 63,913 & $\mathrm{No}^{*}$ \\
\hline 6 & LPB 3 & 98,626 & No* \\
\hline 7 & LPB 4 & 171,080 & $\mathrm{No}^{*}$ \\
\hline 9 & LPB 5 & 110,963 & $\mathrm{No}^{*}$ \\
\hline 10 & LPB 6 & 103,160 & $\mathrm{No}^{*}$ \\
\hline 11 & LPB 7 & 113,866 & $\begin{array}{l}\text { Yes / } \\
\text { Abutment } \\
\text { hex }\end{array}$ \\
\hline 12 & LPB 8 & $38,191^{* *}$ & No \\
\hline 13 & LPB 9 & 89,112 & $\begin{array}{l}\text { Yes / } \\
\text { Abutment } \\
\text { press-fit }\end{array}$ \\
\hline \multirow[t]{2}{*}{ LPB } & $\begin{array}{l}\text { Sample mean / Sample } \\
\text { standard deviation }\end{array}$ & 108,780 & / $\quad 30,617$ \\
\hline & $\begin{array}{l}\text { Sample median / Sample } \\
\text { median absolute deviation }\end{array}$ & 107,060 & / $\quad 10,477$ \\
\hline
\end{tabular}

" The test was automatically stopped due to excessive displacement. No crack was observed in the examined components after the test.

${ }_{* * *}^{*}$ Test specimen LPB 8 was stopped manually before any excessive displacement or indication of failure, at 38,191 cycles to make a fair comparison on the wear with the Control 4 test specimen. This specimen is therefore not included in any other analysis.

region of the fixture, interference profilometry of this surface was performed. The analysis was done on a single segment cut away from the most distal part of the fixture $\left(\sim 20 \mathrm{~mm}\right.$ longitudinal length, $\sim 90^{\circ}$ circumference) using a Wyko NT9100 Optical Profiling System (Veeco Instruments Inc., NY, USA). The measurements were performed in Vertical Scanning Interferometer mode, (VSI) with 10.1 magnification to acquire a profile of the surface in the longitudinal direction (longitudinal sampling distance $0.98 \mu \mathrm{m}$ ). Three parallel profiles were measured with a circumferential distance of $200 \mu \mathrm{m}$ between the profiles. For each profile, the total worn off area was calculated, and subsequently, the projected worn off volume for the entire internal circumference was calculated for each profile. The mean value of the three projected worn off volumes was then calculated for each of the analyzed specimens.

A schematic illustration of the sequence of all study procedures is shown in Fig. 3.

\subsection{Statistical analysis}

No assumption of normal distribution was made for the number of cycles to failure for each of the two groups. The non-parametric twosided Wilcoxon rank sum test was therefore used to compare the number of cycles to failure between the two groups. Sample mean and sample median, sample standard deviation and sample median absolute deviation was calculated for each group.

\section{Results}

\subsection{Residual stress measurement}

The longitudinal residual stress measured at the center of the treated region in one of the LPB treated abutments is shown in Fig. 4. The residual stress was measured from the surface and at discrete depths as indicated in Fig. 4. The highest measured compressive stress was 995 $\mathrm{MPa}$, measured at $51 \mu \mathrm{m}$ depth. Compressive residual stresses were found from the surface down to depths of approximately $400-500 \mu \mathrm{m}$.

\subsection{Rotation bending tests}

The tests were run sequentially as presented in Table 1. For the first three test specimens (Control 1-Control 3), optical microscopy was performed directly following each test, before the subsequent test was started. In each of these three tests, a fatigue crack was found at the distal end of the press-fit region of the abutment. This led to an altered test/inspection sequence, where for the next 7 tests (LPB 1-LPB 6 and Control 4), these were run consecutively without individual inspection of the components before starting subsequent test. Instead, optical microscope inspection of this sequence of tests occurred after the completion of the 10th test. Control 4 specimen exhibited a fatigue crack similar to those previously observed in this group, whereas none of the LPB treated test specimens showed any observable fatigue crack upon inspection. Following this observation, the threshold value of the proximity sensor was increased to avoid that the machine stopped before crack initiation. Test specimens LPB 7 and 9 were tested with this altered procedure. To be able to compare LPB treatment against the Control group after the same number of cycles, one of the LPB specimens (LPB 8) was manually and intentionally stopped after 38,191 load cycles, identical to the number of cycles to failure for one of the specimens in the Control group (Control 4, this test specimen was chosen because the number of cycles to failure for this test specimen was closest to the mean number of cycles to failure within the control group). A comparative evaluation of the wear in the fixture was then conducted by interference profilometry on these two specimens.

The results from the rotation bending tests are presented in Table 1 and Fig. 5. The LPB treated specimens could withstand statistically significantly more load cycles $\left(p=0.004\right.$, Wilcoxon rank sum $=10, \mathrm{n}_{1}=$ $4, \mathrm{n}_{2}=8$, two-tailed) than the non-treated specimens. Comparing the number of load cycles per group, LPB treatment led to $187 \%$ and $171 \%$ improvement in terms of mean and median number of load cycles, respectively.

\subsection{Post-test inspection}

Light microscopy inspection showed that all test specimens in the control group had identical failure modes, a fatigue crack at the distal end of the press-fit region of the abutment (Fig. 6 and Fig. 7). Of the LPB treated specimens, only LPB 7 and 9 had observable fractures. In LPB 7, the crack was found in the distal region of the hex of the abutment, and it propagated to a full fracture when the abutment was extracted from the fixture. In LPB 9, a fatigue crack was formed in the distal region of the press-fit region of the abutment at a location similar to that of the specimens in the control group. The fatigue crack grew to a fracture when the specimen was removed from the test rig. Due to the homogeneousness in the results within the control group it was judged sufficient to perform post-test SEM inspection and interference profilometry on one specimen in this group. The specimen with cycles to failure closest to the sample mean was selected, assuming that this specimen would be representative for the sample. From the LPB group, after first excluding the test specimens withstanding the least (LPB 2) and the most (LPB 4) number of load cycles, two test specimens were randomly selected for SEM and interference profilometry evaluation (LPB 1 and 9). To compare between groups after the same number of to load cycles, test 


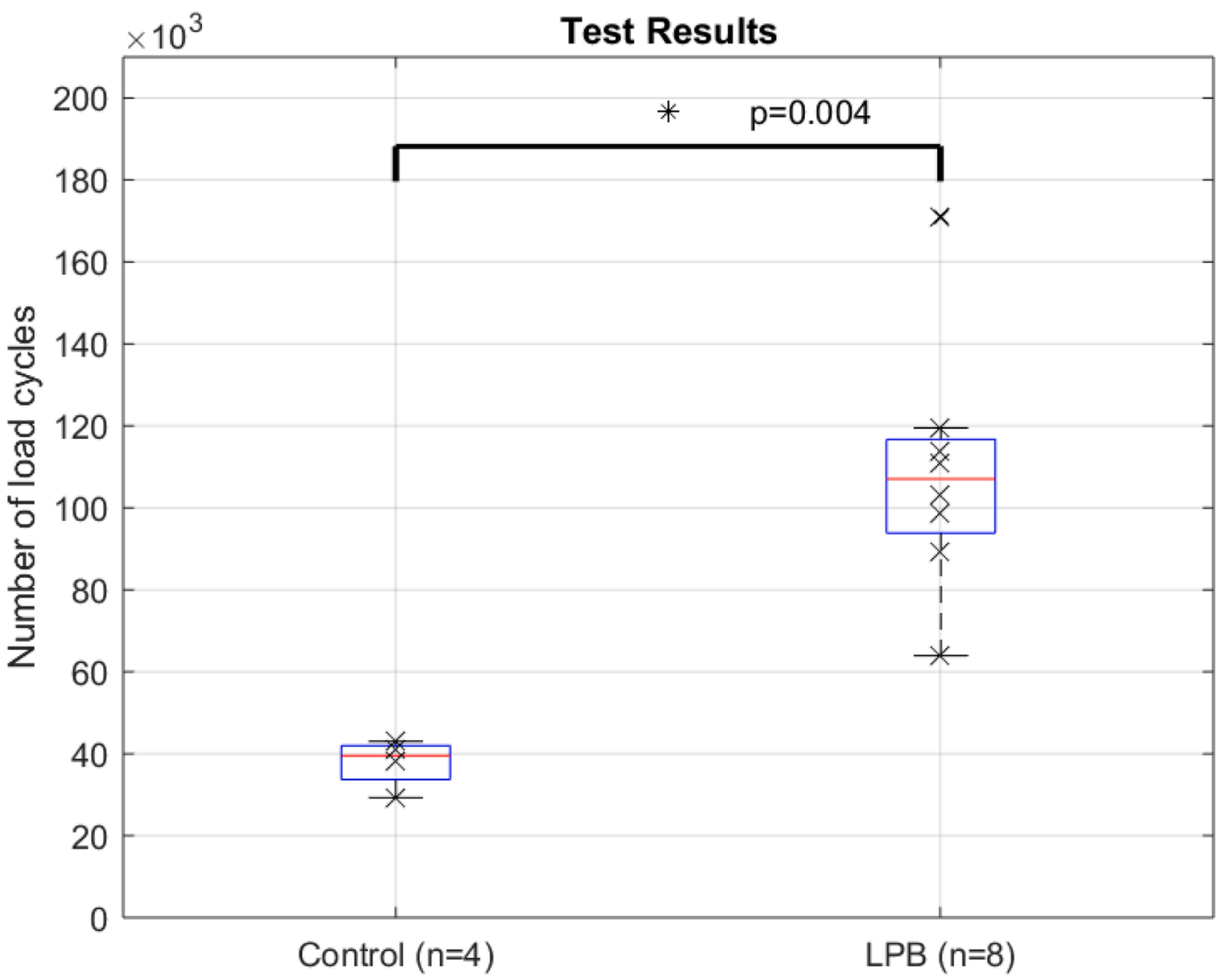

Fig. 5. Boxplot showing the number of load cycles in the rotation bending tests. Each test is denoted with a black "x", the median is denoted with a horizontal red line.

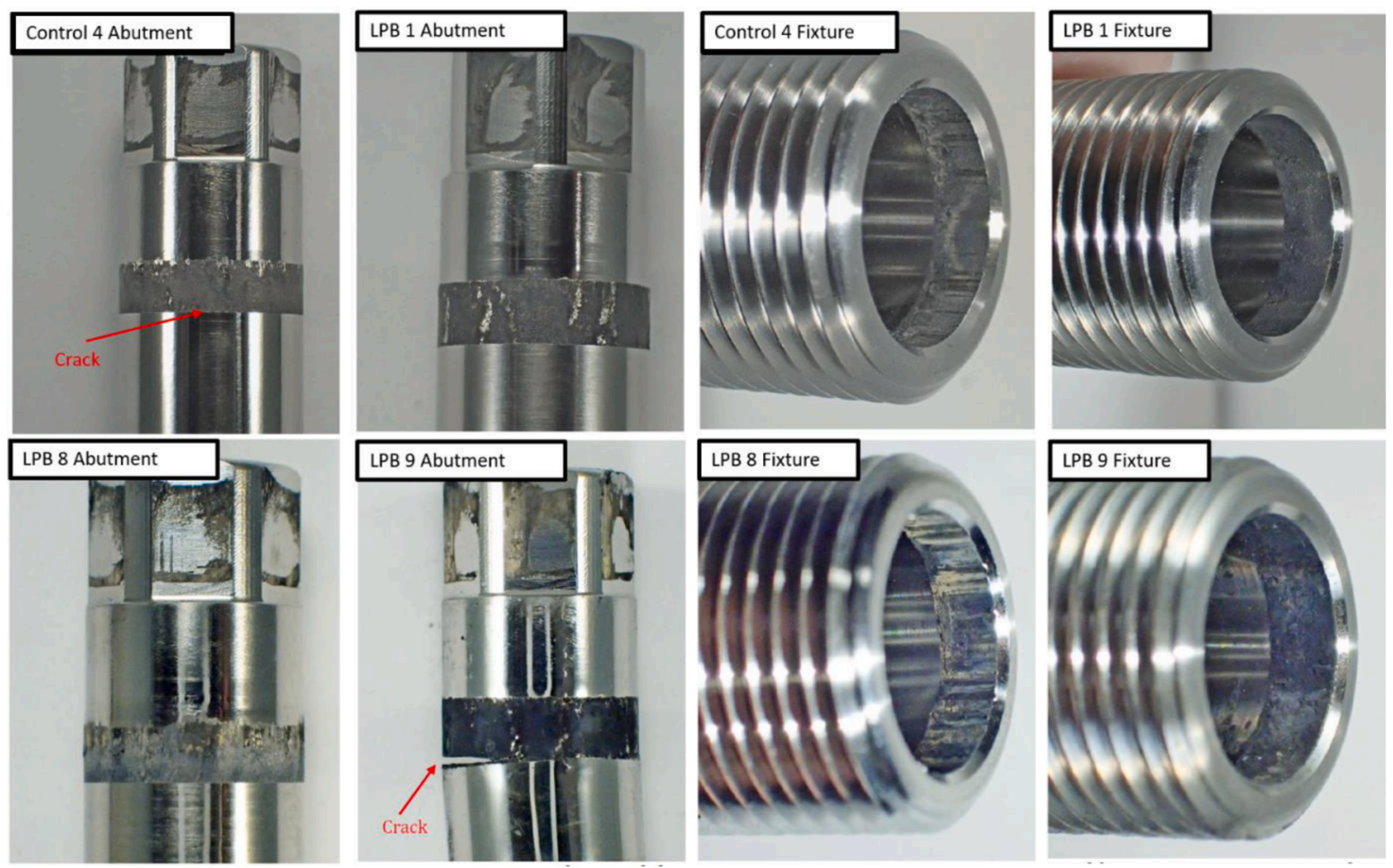

Fig. 6. Proximal end of the abutments (to the left) and distal end of the fixtures (to the right) of the test specimens that underwent detailed post-test inspection. 


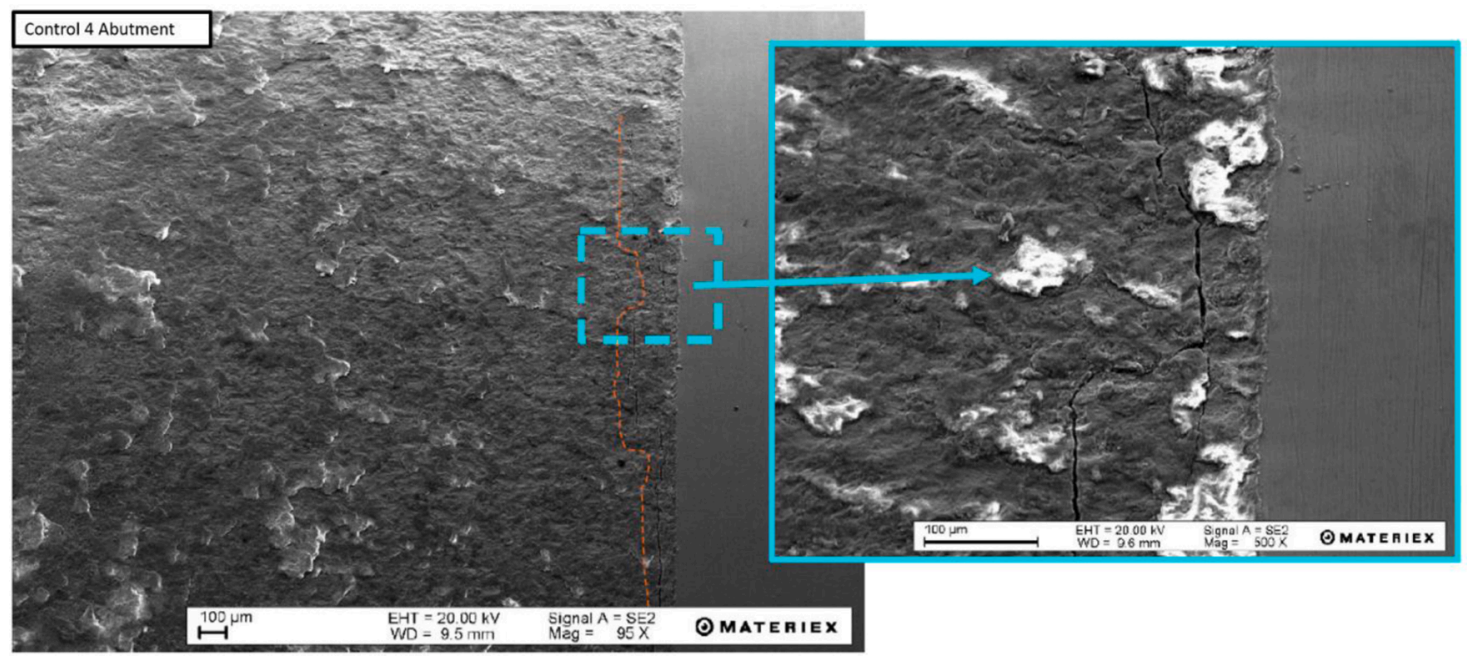

Fig. 7. SEM image of the fatigue crack in the abutment of Control 4 test specimen.
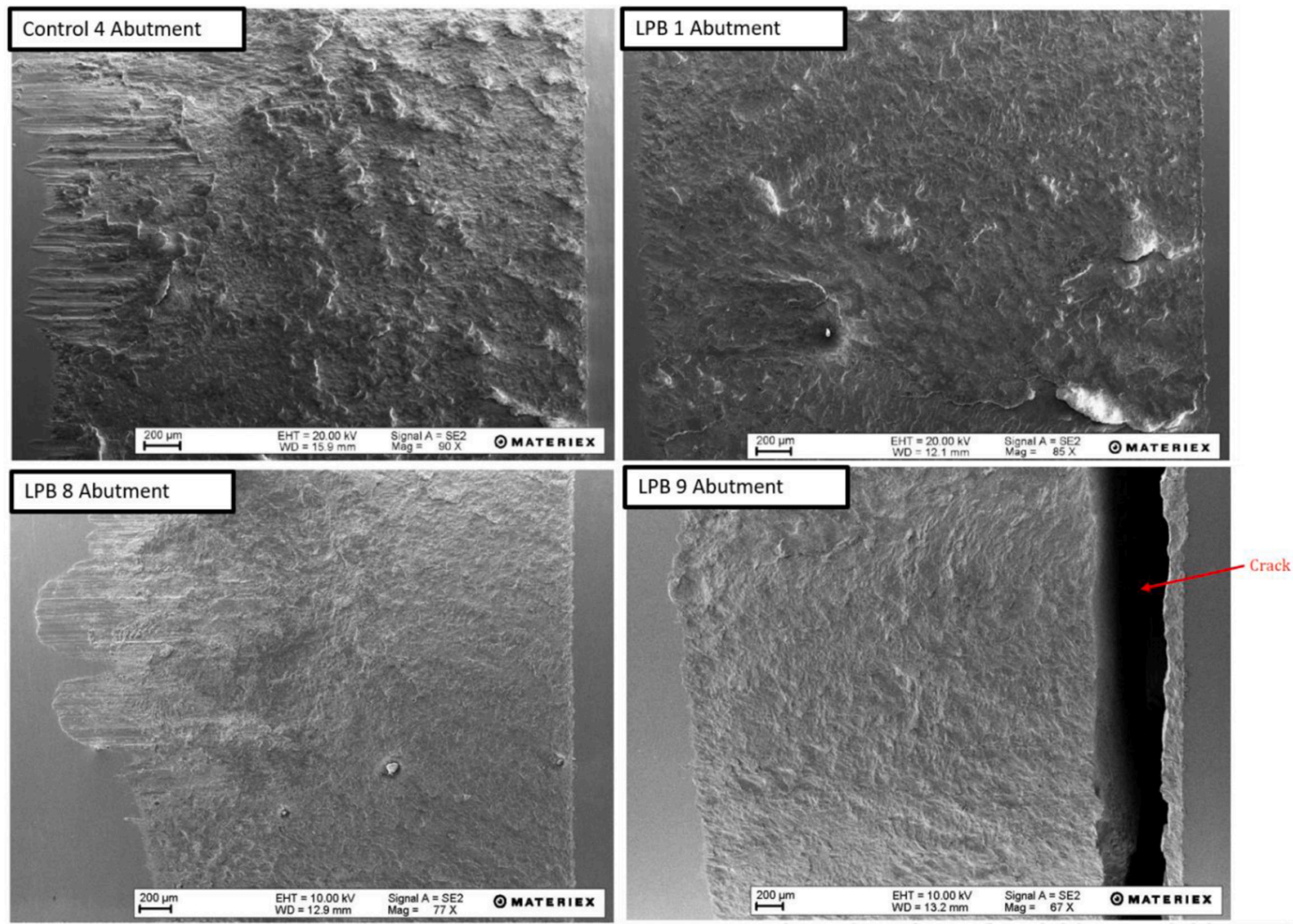

Fig. 8. SEM images of the press-fit regions of the four abutments that underwent SEM evaluation.

specimen LPB 8 was also included in the evaluation. Images of contact regions of the abutment and fixture in the four inspected test specimens are presented in Fig. 6 and Fig. 7.

The press-fit areas of both fixtures and abutments from all examined specimens had similar circumferential wear bands. There was no trace of the original surface left in the worn areas of abutment or fixture in any of the examined test specimens. The qualitative SEM evaluation concluded that the contact surfaces of the fixture and abutments were damaged by predominantly adhesive wear (fretting), with some axial scratches that likely originate either from the mounting or the removal of the abutment into/out of the fixture. The abutment of test specimen Control 4 had a substantially rougher surface morphology in the contact region than the
LPB-treated abutments (Fig. 8).

\subsection{Profilometry results}

The profilometry profiles are shown in Fig. 9, with results presented in Fig. 10, Fig. 11, and Table 2. LPB 8 and Control 4 had undergone the same number of load cycles, but the mean projected volume of worn off material for LPB 8 was approximately one fifth of corresponding value for Control 4. The projected worn off volumes of LPB 1 and LPB 9 were 2.5 and 2.2 times the value of Control 4, respectively. 

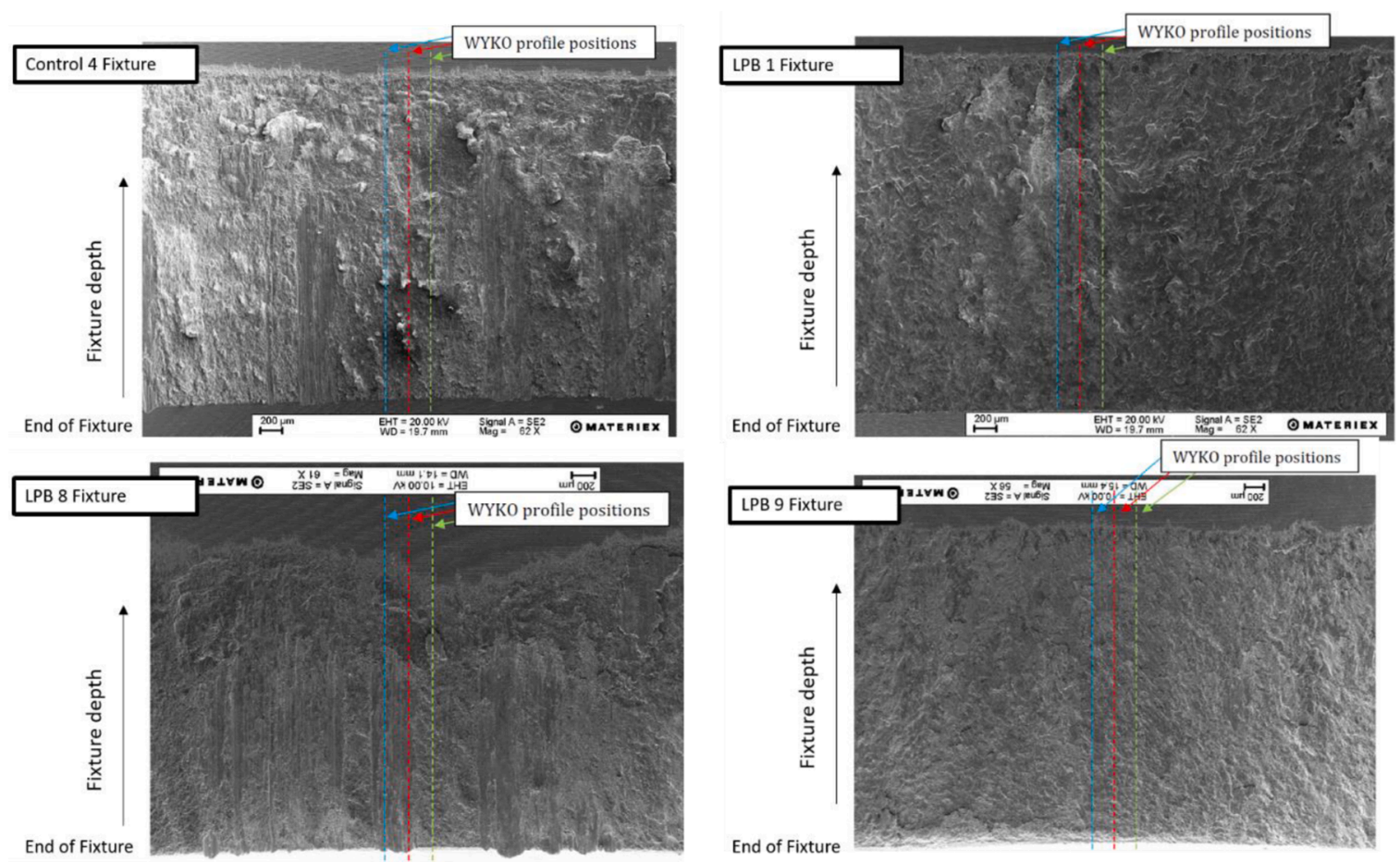

Fig. 9. Locations of the profile paths from the fixtures which underwent interference profilometry.
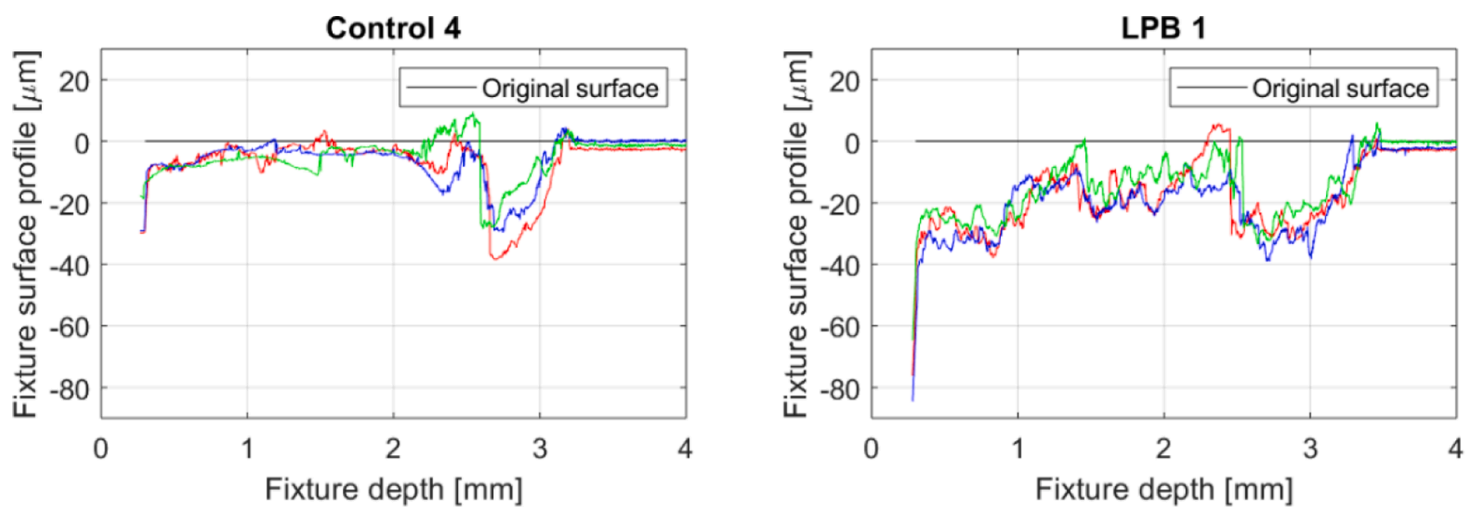

LPB 8
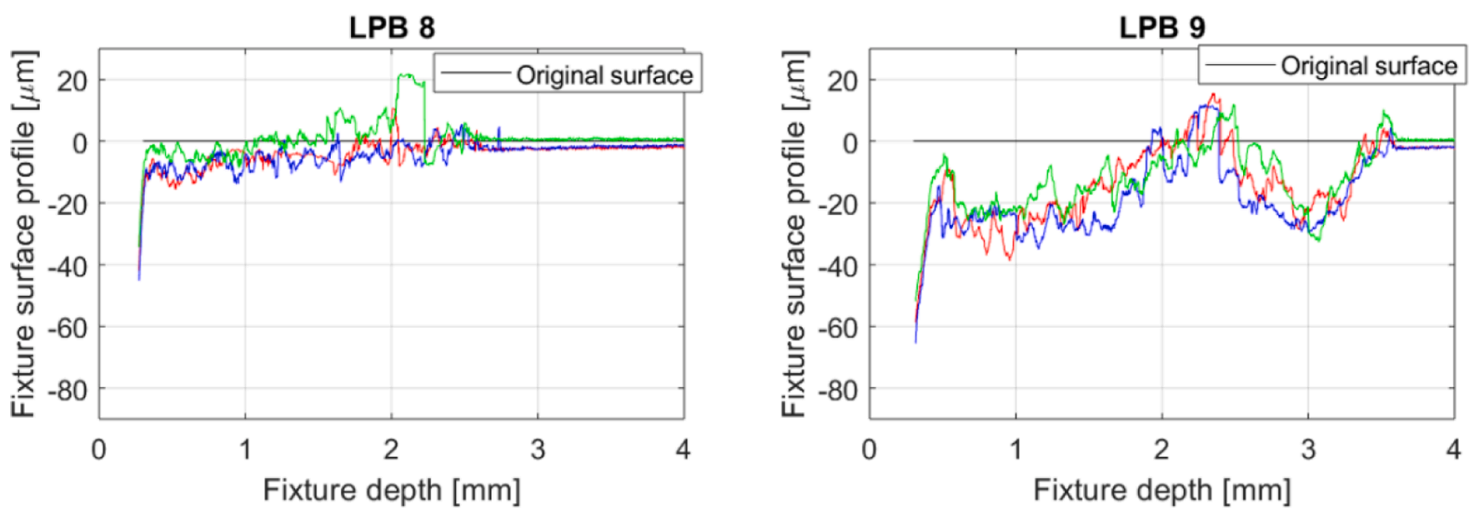

Fig. 10. Longitudinal interference profilometry surface profiles from the positions indicated in Fig. 9.

\section{Discussion}

We conducted an experimental evaluation of the effect of LPB treatment on fretting fatigue resistance and wear in modular implants for bone-anchored attachment of limb prostheses. The results from the rotation bending tests showed that the treatment led to statistically significant improvements compared with the untreated specimens. All LPB treated specimens surpassed the number of cycles that any of the specimens in the control group could withstand. The improvement was $187 \%$ and $171 \%$ in terms of mean and median number of load cycles, respectively, which may be regarded as conservative due to the fact that six of the eight specimens in the LPB group had not developed a fatigue 


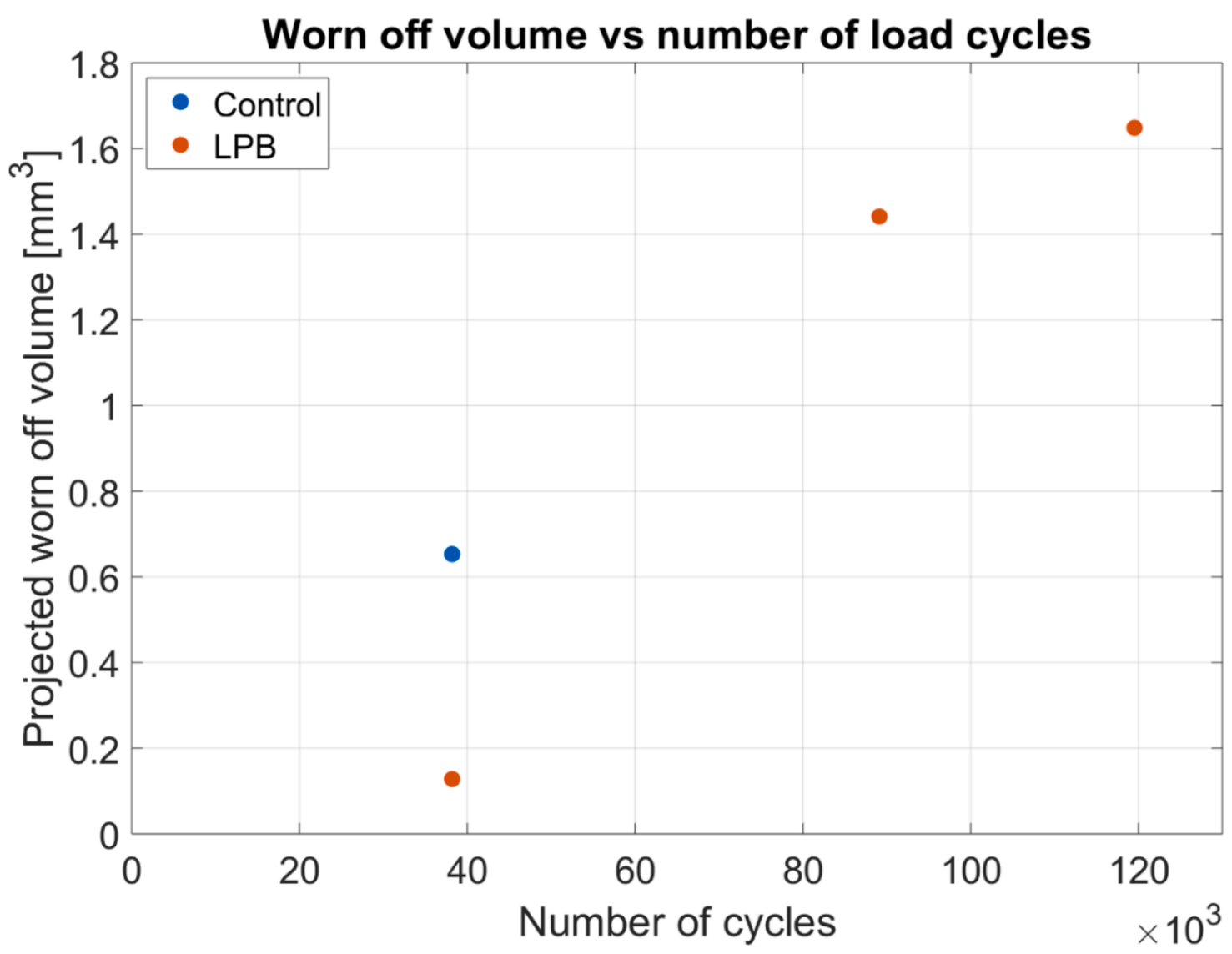

Fig. 11. Mean projected worn off volume and number of load cycles for each of the fixtures that underwent interference profilometry.

Table 2

\begin{tabular}{|c|c|c|c|c|c|c|c|}
\hline \multirow[b]{2}{*}{ Test Specimen } & \multicolumn{3}{|c|}{ Worn off material $\left(\mu \mathrm{m}^{2}\right)$} & \multicolumn{4}{|c|}{ Projected worn off volume $\left(\mathrm{mm}^{3}\right)$} \\
\hline & Blue profile & Red profile & Green profile & Blue profile & Red profile & Green profile & Mean \\
\hline Control 4 & 22,800 & 17,400 & 16,500 & 0.788 & 0.601 & 0.570 & 0.653 \\
\hline LPB 1 & 47,200 & 45,800 & 50,100 & 1.631 & 1.583 & 1.731 & 1.648 \\
\hline LPB 8 & 4,300 & 3,100 & 3,700 & 0.149 & 0.107 & 0.128 & 0.128 \\
\hline LPB 9 & 49,000 & 38,600 & 37,500 & 1.693 & 1.334 & 1.296 & 1.441 \\
\hline
\end{tabular}

crack at the end of the test. In these tests, the excessive vertical displacement causing the test machine to stop before crack initiation was most likely an effect of the wear in the connection between the fixture and the abutment which allowed for more displacement within the joint. More load cycles naturally lead to more wear in the fixture, and this was consistent with the profilometry measurements.

A limitation of the profilometry measurements was that the wear measurements were only performed on four test specimens, and they were limited to three parallel profiles within a small segment. Despite the small spacing between the profiles, there was notable variation in the extent of wear between profiles within the same specimen. Extrapolating the wear from these profiles to a volume around the circumference of the fixture adds uncertainty and the results from the wear analysis should be considered in this context. However, the mean projected worn off volume in the fixture of the LPB 8 specimen was one fifth of the corresponding volume in the Control 4 specimen for the same number of load cycles, indicating that there may be a substantial difference in the wear between the groups. This favours the LPB treatment and may offer a partial explanation for why this group could sustain a larger number of load cycles. The SEM analysis of the surfaces of the abutments showed that the analyzed abutment in the control group had a rougher surface compared with the abutments in the LPB treated group after the tests. The residual stress measurement showed that the LPB process induces compressive stresses to depths up to around $400 \mu \mathrm{m}$ in the center of the treated region, this implies that even when some material is worn off from the original surface, there is still compressive stresses in the underlying material which may prevent fatigue crack initiation.

A limitation of the study is that the tests were performed in dry conditions at room temperature rather than in a setting mimicking the conditions in the human body which constitutes a more corrosive environment. The study is thereby limited to study the effect of LPB on the resistance to fretting-fatigue rather than fretting-corrosion-fatigue. Another limitation is that the test loads and the boundary conditions differ from the real-world scenario. In the test setup a proximal portion of the fixture is rigidly clamped while the rest of the test specimen has no support at all. This does not mimic a real-world scenario where the fixture is surrounded by cortical bone, which provides additional support and reduces the stress in the implant. The rotation bending test introduces mostly longitudinal tensile and compressive stresses with maximum values along the full circumference of the test specimen. On the other hand, a real-world load scenario for example corresponding to normal gait, introduces forces in several directions, torsional moments, and bending moments constrained to one or two planes which naturally 
lead to a different stress state. However, large variations in body weight, anatomy, bone quality, activity levels and gait parameters make it challenging to generalize real-world loading of the implant to a single load cycle. A more fruitful approach is to reduce the load profile to include only components that have a substantial effect on the stress state. Since the bending loads are the main contributor to the stress state during repetitive ambulatory loading [30-33], the test results using the rotation bending method might have relevance for clinical loading conditions. If the improvements observed in this study can be achieved in clinical settings, it may lead to fewer revisions of implanted components, a reduced number of hospital visits and reduced time being immobilized waiting for component replacement for the user. Since the treatment is applied to the abutment which is replaceable, both current and future users of bone-anchored implant system could potentially benefit from this treatment if implemented.

\section{Conclusion}

The results from rotation bending tests showed that LPB treatment of the abutment of a bone-anchoring implant system led to statistically significantly enhanced resistance to fretting fatigue, as compared to specimens with untreated abutments. Wear analyses indicated that LPB treatment reduced wear in comparison with the untreated condition. While the test results may not be directly extrapolated to a real-world scenario due to differences in the tested conditions as compared with the conditions during clinical use, the magnitude of the improvement observed within this evaluation, makes substantial improvements in a real-world scenario probable. If improvements can be translated to clinical settings it may lead to reduced need of implant component revision for current and future users of systems for bone-anchored attachment of amputation prostheses in the future.

\section{Funding}

Research supported by the Promobilia Foundation, the IngaBritt and Arne Lundbergs Foundation, the Swedish Foundation for Strategic Research (SSF), the Swedish Innovation Agency (VINNOVA), the Swedish Research Council (Vetenskapsrådet) and Integrum AB.

\section{Ethical approval}

Not required

\section{Declaration of Competing Interest}

Alexander Thesleff reports a relationship with Integrum AB that includes: employment and equity or stocks. Max Ortiz-Catalan reports a relationship with Integrum $\mathrm{AB}$ that includes: consulting or advisory and equity or stocks. Rickard Brånemark reports a relationship with Integrum $A B$ that includes: board membership and equity or stocks.

\section{Acknowledgement}

The authors thank Oddbjörn Hallenstvedt for preparation of the test rig, and Marta Björnsdottir and Sebastian Brånemark for assistance in performing the rotation bending tests.

\section{References}

[1] Dillingham TR, Pezzin LE, Mackenzie EJ, Burgess AR. Use and satisfaction with prosthetic devices among persons with trauma-related amputations a long-term outcome study. Am J Phys Med Rehabil 2001;80(8):563-71.

[2] Pezzin LE, Dillingham TR, MacKenzie EJ, Ephraim P, Rossbach P. Use and satisfaction with prosthetic limb devices and related services. Arch Phys Med Rehabil 2004. https://doi.org/10.1016/j.apmr.2003.06.002.

[3] Meulenbelt HEJ, Geertzen JHB, Jonkman MF, Dijkstraa PU. Skin problems of the stump in lower limb amputees: 2. influence on functioning in daily life. Acta Derm. Venereol. 2011. https://doi.org/10.2340/00015555-1023.
[4] Hoaglund FT, Jergesen HE, Wilson L, Lamoreux LW, Roberts R. Evaluation of problems and needs of veteran lower-limb amputees in the San Francisco Bay Area during the period 1977-1980. J Rehabil R D 1983.

[5] Dudek NL, Marks MB, Marshall SC, Chardon JP. Dermatologic conditions associated with use of a lower-extremity prosthesis. Arch Phys Med Rehabil 2005; 86(4):659-63. https://doi.org/10.1016/j.apmr.2004.09.003.

[6] Hagberg K, Brånemark R. Consequences of non-vascular trans-femoral amputation: a survey of quality of life, prosthetic use and problems. Prosthet Orthot Int 2001;25 (3):186-94. https://doi.org/10.1080/03093640108726601.

[7] “Osseointegration," Merriam-Webster Medical Dictionary. https://www.merri am-webster.com/medical/osseointegration (accessed Mar. 22, 2021).

[8] Brånemark PI, et al. Osseointegrated implants in the treatment of the edentulous jaw. Experience from a 10-year period Scand J Plast Reconstr Surg Suppl 1977;16: $1-132$.

[9] Eriksson E, Brånemark P-I. Osseointegration from the perspective of the plastic surgeon. Plast. Reconstr. Surg. 1994;93(3):626-37. https://doi.org/10.1097/ 00006534-199493030-00033.

[10] Hagberg K, Hansson E, Brånemark R. Outcome of percutaneous osseointegrated prostheses for patients with unilateral transfemoral amputation at two-year followup. Arch Phys Med Rehabil 2014;95(11):2120-7. https://doi.org/10.1016/j. apmr.2014.07.009.

[11] Brånemark RP, Hagberg K, Kulbacka-Ortiz K, Berlin Ö, Rydevik B. Osseointegrated percutaneous prosthetic system for the treatment of patients with transfemoral amputation. J Am Acad Orthop Surg 2018;00(00):1. https://doi.org/10.5435/ JAAOS-.

[12] Hagberg K, Brånemark R. One hundred patients treated with osseointegrated transfemoral amputation prostheses - rehabilitation perspective. J Rehabil Res Dev 2009. https://doi.org/10.1682/JRRD.2008.06.0080.

[13] Van de Meent H, Hopman MT, Frölke JP. Walking ability and quality of life in subjects with transfemoral amputation: a comparison of osseointegration with socket prostheses. Arch Phys Med Rehabil 2013;94(11):2174-8. https://doi.org/ 10.1016/j.apmr.2013.05.020.

[14] Al Muderis M, et al. The Osseointegration group of Australia accelerated protocol (OGAAP-1) for two-stage osseointegrated reconstruction of amputated limbs. Bone Joint J 2016;98-B(7):952-60. https://doi.org/10.1302/0301-620X.98B7.37547.

[15] Al Muderis M, Lu W, Li JJ. Osseointegrated prosthetic limb for the treatment of lower limb amputations : experience and outcomes. Unfallchirurg 2017;120(4): 306-11. https://doi.org/10.1007/s00113-016-0296-8.

[16] Palmquist A, Windahl SH, Norlindh B, Brånemark R, Thomsen P. Retrieved boneanchored percutaneous amputation prosthesis showing maintained osseointegration after 11 years-a case report. Acta Orthop 2014;85(3):442-5. https://doi.org/10.3109/17453674.2014.919559.

[17] Prevéy P, Telesman J. FOD resistance and fatigue crack arrest in low plasticity burnished IN718. Proceedings of the 5th National Turbine Engine High Cycle Fatigue Conference Chandler, AZ, March 7-9 2000:2000.

[18] Hagberg K, Jahani S-AGhassemi, Kulbacka-Ortiz K, Thomsen P, Malchau H, Reinholdt C. A 15-year follow-up of transfemoral amputees with bone-anchored transcutaneous prostheses. Bone Joint J 2020. https://doi.org/10.1302/0301620x.102b1.bjj-2019-0611.r1.

[19] Thesleff A, Brånemark R, Håkansson B, Ortiz-Catalan M. Biomechanical characterisation of bone-anchored implant systems for amputation limb prostheses: a systematic review. Ann Biomed Eng 2018:1-15. https://doi.org/10.1007/ s10439-017-1976-4.

[20] Waterhouse RB. Fretting fatigue. Int Mater Rev 1992. https://doi.org/10.1179/ imr.1992.37.1.77.

[21] Hoeppner DW, Chandrasekaran V. Fretting in orthopaedic implants: a review. Wear 1994. https://doi.org/10.1016/0043-1648(94)90272-0.

[22] H. Meyer, T. Mueller, G. Goldau, K. Chamaon, M. Ruetschi, and C.H. Lohmann, "Corrosion at the cone/taper interface leads to failure of large-diameter metal-onmetal total hip arthroplasties," 2012. doi: 10.1007/s11999-012-2502-5.

[23] Bishop N, et al. Wear patterns of taper connections in retrieved large diameter metal-on-metal bearings. J Orthop Res 2013. https://doi.org/10.1002/jor.22326.

[24] Withers PJ. Residual stress and its role in failure. Rep Prog Phys 2007;70(12): 2211-64. https://doi.org/10.1088/0034-4885/70/12/R04.

[25] Prevéy PS, Jayaraman N, Ravindranath RA, Shepard M. Mitigation of fretting fatigue damage in blade and disk pressure faces with low plasticity burnishing. J Eng Gas Turbine Power 2010. https://doi.org/10.1115/1.2943154.

[26] N. Jayaraman et al., "Mitigation of fatigue and pre-cracking damage in aircraft structures through low plasticity burnishing (LPB)," no. 513, 2007.

[27] Hornbach D, Prevey P, Loftus E. Fatigue performance improvement of Ti-6Al-4 V femoral hip stems via low plasticity burnishing (LPB). Medical Device Materials IV: Proceedings of the Materials and Processes for Medical Devices Conference 2007 2008:166-70. https://doi.org/10.1361/cp2007mpmd166.

[28] P.S. Prevéy, "The effect of cold work on the thermal stability of residual compression in surface enhanced IN718," 2000.

[29] Prevey PS. X-Ray diffraction residual stress techniques. Mater Charact 2018. https://doi.org/10.31399/asm.hb.v10.a0001761.

[30] Thesleff A, Haggstrom E, Tranberg R, Zugner R, Palmquist A, Ortiz-Catalan M. Loads at the implant-prosthesis interface during free and aided ambulation in osseointegrated transfemoral prostheses. IEEE Trans Med Robot Bionics 2020. https://doi.org/10.1109/tmrb.2020.3002259. 
[31] Lee WCC, et al. Magnitude and variability of loading on the osseointegrated implant of transfemoral amputees during walking. Med Eng Phys 2008;30(7): 825-33. https://doi.org/10.1016/j.medengphy.2007.09.003.

[32] Frossard L. Loading characteristics data applied on osseointegrated implant by transfemoral bone-anchored prostheses fitted with basic components during daily activities. Data Brief 2019. https://doi.org/10.1016/j.dib.2019.104492.
[33] Stenlund P, Trobos M, Lausmaa J, Brånemark R, Thomsen P, Palmquist A. The effect of load on the bone-anchored amputation prostheses. J Orthop Res 2016;35 (5):1113-22. https://doi.org/10.1002/jor.23352. 